\title{
Eruption patterns of parasitic volcanoes
}

\author{
Izumi Yokoyama
}

The Japan Academy, Ueno Park, Tokyo, Japan

\section{Article history}

Received April 28, 2014; accepted May 28, 2015.

Subject classification:

Parasitic vents, Parasitic eruptions, Shear fracture model, Twin parasitic vents, Various patterns of parasitic eruptions.

\section{ABSTRACT}

Eruption patterns of parasitic volcanoes are discussed in order to study their correlation to the activities of their parental polygenetic volcanoes. The distribution density of parasitic vents on polygenetic volcanoes is diversified, probably corresponding to the age and structure of parental volcanoes. Describing existing parasitic cones contextually in relation to parental volcanoes is as indispensable as collecting observational data of their actual formations. In the present paper, spatial distributions of parasitic cones are classified tentatively into the following three categories: individually radial, directionally radial and annular determined according to feature's placement around the central axes of the parental volcanoes. The formations of parasitic vents are discussed from the standpoint of material mechanics. Derived from this approach, the maximum shear stress model suggests the possibility of twin parasites, and their existence on particular volcanoes verifies the possible validity of this interpretation though it may be not necessarily universally applicable to every volcano due to various effects of volcanism and lack of complexity in the model. Some characteristics of parasitic eruptions are discussed, such as monogenetic activity of parasitic vents and simultaneous eruptions of summit craters and parasitic vents. Parasitic volcanism proves to be not merely an auxiliary feature of its parental volcano but closely correlated with magma plumbing systems.

\section{Introduction}

"Parasitic volcanoes" are volcanic features forming vents, craters, cones, domes and mounds of varying diameter and height situated either beside the main cones or at the flanks and bases of volcanoes; explosions, effusions and dome structures will accompany these formations. The present discussion is unconcerned with parasitic cone growth and instead concentrates on the process of creation. Formation mechanisms of parasitic vents may be closely related to activities of the main craters.

Often parasitic volcanoes are so small in volume that their remnants may disappear after many centuries and hence they have been deemed as secondary in volcanic activities. Thus parasitic cone formation events, both presently and in the historical record, necessarily have not been recorded in detail. Therefore, the present author's discussion is inevitably limited to exemplification of specific active volcanoes. There are examples of exceptionally large magnitude parasitic eruptions emanating from small parasitic vents. In the 1914 eruption of Sakurajima volcano, Japan, the two parasitic vents were extraordinarily vigorous and ejected lava over a volume of about $2 \mathrm{~km}^{3}$ for about 25 days.

Empirically we know that parasitic vents are usually monogenetic i.e. they would no more erupt after their cycles of activity though the observation ages are not sufficiently long to be conclusively certain. It is probably because a parasitic vent is usually small in diameter and connected to a thin sub-conduit that branched from the main conduit at a certain depth. Furthermore, around the branch point of the sub-conduit, magma intrusions may mechanically strengthen the surrounding ground due to their "piling effects", and a new parasitic sub-conduit cannot take the same route for the surface,

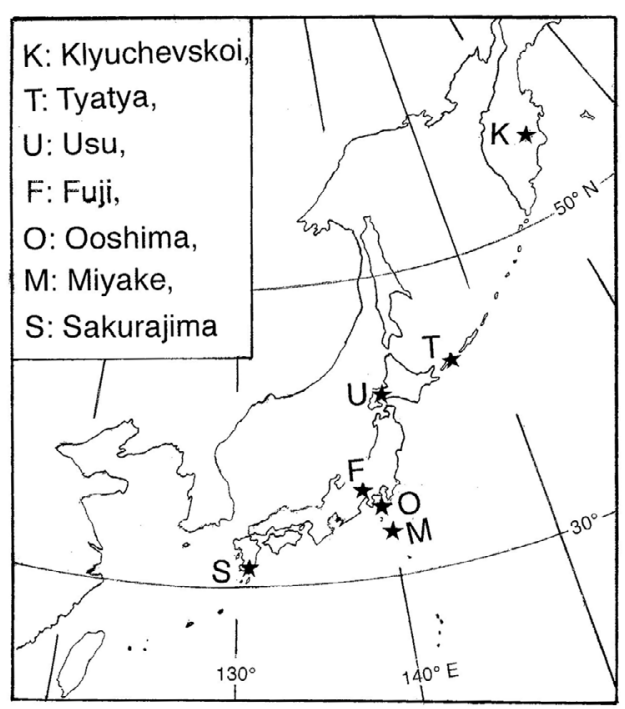

Figure 1. Location map in the eastern Asia. 
and searches a parasite-free point, that is "parasite gap". This may be a plausible reason for parasitic vents erupting only in a cycle of activity. We require more circumstantial evidence for definite confirmation. Eruption patterns of parasitic volcanoes have been examined from diverse viewpoints, two examples being as a spatiotemporal series of parasitic eruptions [Takada 1997] and alternatively as a morphometry of parasitic cones [Fornaciai et al. 2012]. In the present paper, structural origins of parasitic vents are elucidated mainly on the basis of their spatial distribution whereas simultaneous occurrences of main crater and parasitic vents are examined based upon their spatiotemporal relationship.

\section{Spatial distribution of parasitic vents}

Distributions of parasitic vents on polygenetic volcanoes are various: rather simple on some volcanoes and apparently irregular on other volcanoes. It is natural that distributions of parasites depend on the ages and the eruption patterns of parental volcanoes. On some young volcanoes, parasitic vents are increasing in number and exhibiting a tendency in geological time scales. Therefore, in order to discuss characteristics of their spatial distributions, we cannot apply dexterous and simplistic methods such as cluster analyses and two-dimensional Fourier analyses. The author follows the assumptive principle that volcano edifices are originally constructed symmetrically with respect to the central axes of volcanoes and so the distribution of parasites should be controlled by radius not by azimuth if there are no particular anisotropies in local or regional tectonic structures.

Classification of spatial distribution of parasitic vents: in the following sections we will classify their spatial distributions into three categories (individually radial, directionally radial and annular) and exemplify each according to apparent features of the distributions with reference to central axes of the parental volcanoes.

\subsection{Individually radial distribution centering at the} axes of volcanoes

Individually radial parasitic vents appear on eruptive fissures distributed in a radial direction from the center of a volcano, but they don't show any systematic trends as a whole. There is a tendency for these formations to ultimately reach unidirectional or uniform distribution in future depending on the volcanic activity of the parental volcanoes. Two large volcanoes, Fuji and Etna, will be exemplified.

Fuji (3776 m a.s.1.), central Japan: this volcano measures about $40 \mathrm{~km}$ in basal diameter and is a typical steep-sided composite volcano that is underlain by two older volcanoes. Its rocks are rather uniform and basaltic.
The present Fuji (the Younger Fuji) is on the order of $10^{4}$ yr. B.P. [Machida and Arai 1992] and its large, single peak has produced several parasites in prehistoric periods, however few have been recently formed. Tsuya $[1943,1955]$ recorded 82 parasites on this volcano as shown in Figure 2. Around 10,000 yr. B.P., a large amount of fluidal lava flows issued from the summit and reached $30 \mathrm{~km}$ from the $S$ base. More recently, there are 10 historical records of eruptions dating back to 781 A.D. The physical debris and hollows produced by some of these eruptions remain topographically. For instance, the 864 866 eruption extruded $1.2 \mathrm{~km}^{3}$ lava which covered an area of $32 \mathrm{~km}^{2}$, and formed the parasitic cone Mt. Nagao (1424 m a.s.l. being about $120 \mathrm{~m}$ in relative height, $\mathrm{N}$ in Figure 2) at the NW foot. The 1707 eruption ejected $0.7 \mathrm{~km}^{3}$ of pumice, bombs, lapilli and diverse ash in total, and produced the "Ho-ei" crater $(\mathrm{H}$ in Figure 2) composed of three small craters located at the SE part of the summit between the altitudes of 2500 and 3000 meters a.s.l. The magnitude of the last eruption was of the primary class and resulted in ash fall events in Edo (where Tokyo exists today) located $100 \mathrm{~km} \mathrm{E}$ of Fuji.

The parasitic cones of Fuji are distributed in individual and radial direction or, from another viewpoint, in a NW-SE trend and in its orthogonal one. It is rather difficult to find any decisively predominant direction as shown in Figure 2.

To examine spatial distribution of parasitic cones, the author adopts the principle that volcanic activity generally derives from the magma working along the central conduit of the parental volcano. Then their ra-

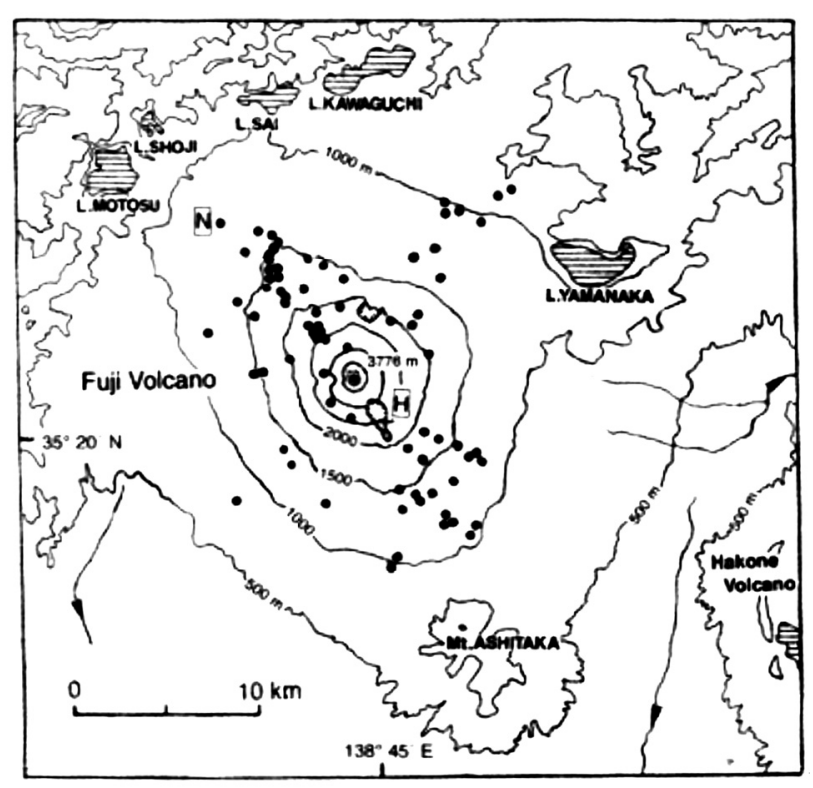

Figure 2. Distribution of parasitic vents on Fuji volcano after Tsuya [1943]. N: the 864 parasite Mt. Nagao; H: the 1707 parasite Mt. Hoei. Ashitaka volcano is Pleistocene. 
dial density shall be counted as the number of parasitic cones per $\mathrm{km}^{2}$ in an annular zone of equidistant circles. The distribution on Fuji is plotted against the radial distance from the center of the volcano as shown in Figure 3 where relatively dense ranges are $1 \sim 7 \mathrm{~km}$ from the center, and a monotonously decreasing tendency is present further than $7 \mathrm{~km}$. $\mathrm{H}$ crater belongs to an active range and $\mathrm{N}$ cone belongs to the inactive range near the base.

Future eruptions of Fuji may occur at the summit crater and otherwise statistically a parasitic vent may open anywhere within this "parasite gap" and probably within the range of $5 \mathrm{~km}$ radius from the center. We cannot deny the possibility of a simultaneous eruptions occurring at the summit crater and a parasitic vent, though the historical record has not recorded such an event.

Etna (3343 m a.s.1.), Sicily: this is about $40 \mathrm{~km}$ of the basal diameter, similar to Fuji, and the rocks are mainly andesine basalt. Its age is reported to be in the order of $10^{6}$ yr. B.P. by Imbò [1965] and is therefore much older than Fuji. Research papers on Etna are too many to enumerate even when limited to the discussions of parasitic volcanisms. There are more parasitic vents than Fuji. Imbò $[1928,1965]$ mentioned 266 parasites on Etna, and tabulated the activities of 129 events recorded during 693 B.C. to 1955 , with the most reliable data being recorded after 1250 A.D. The distribution of the parasitic vents on Etna as of 1999 is shown in Figure 4, redrawn from Azzaro [2004] with some simplifications.

In Figure 4, it is rather difficult to find decisively predominant directions, and many combinations of 2 or 3 parasitic vents are in rows connected by "eruptive fissures" which are radial from the central crater (C.C.). Branca and Del Carlo [2004] compiled eruptions of Etna during the past 3200 years, and especially referred to parasitic eruptions. Corazzato and Tibaldi [2006] discussed distribution of parasitic cones in general and also concerning Etna. One of their conclusions was that morphological types of parasitic cones are related to the underlying fractures.

The density distribution of parasitic cones on Etna compared with the radial distance is shown in Figure 3, where contrasts between populations of parasites in Etna and Fuji, prompt a question. The results are probably affected by both the difference in their ages and by the difference in their activity levels. With Etnean parasites, the density is remarkably predominant in the range of $5 \sim 6 \mathrm{~km}$ from the center. As shown in Figure 4, they are distributed roughly between the $1000 \mathrm{~m}$ and $2000 \mathrm{~m}$ contours, and NE, W and $\mathrm{S}$ in direction. The density distribution peak of the parasites at $r=13.5 \mathrm{~km}$

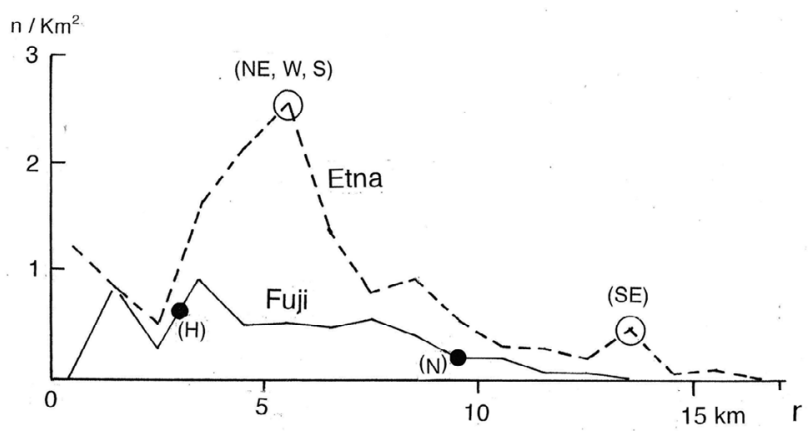

Figure 3. Spatial density distribution $\left(\mathrm{n} / \mathrm{km}^{2}\right)$ of parasitic vents on Fuji and Etna against radial distance from the central axes of the volcanoes. $(\mathrm{H})$ and $(\mathrm{N})$ are the historical eruptions of Fuji. (NE, W, S) and $(\mathrm{SE})$ show the radial directions of the predominant zones on Etna.

is rather small but corresponds to a dense distribution in the range between 500 1000 m contours and centering at the SE flank. This group of about 40 parasites is separated from the central group. On the other hand, Behncke and Neri [2003] studied the 2001 eruption of Etna and assumed a shallow central magma reservoir for the summit eruptions and eccentric shallow one for eccentric eruptions on the SE flank. Yokoyama [1962] analyzed geomagnetic anomalies on Etna observed by Petrucci [1935] and concluded the presence of shallow magma intrusions in the structure of the volcanic system at the summit area and the SE flank where parasitic cones are densely distributed. Beneath the SE area,

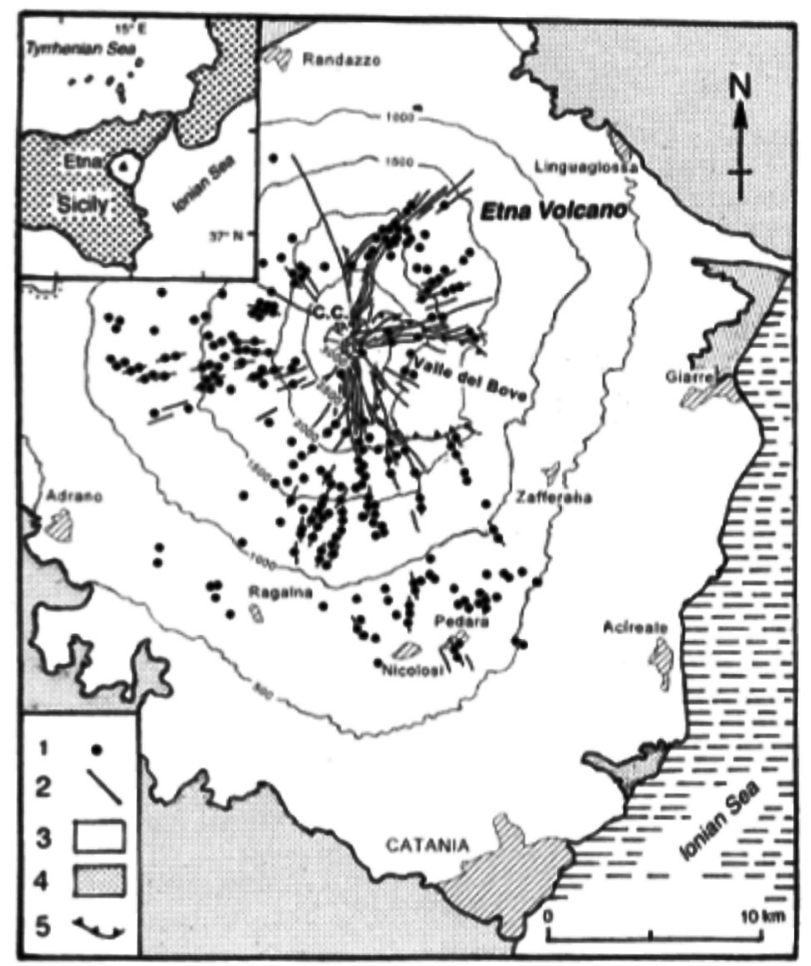

Figure 4. Distribution of parasitic vents on Etna after Azzaro [2004] partly modified: 1) parasitic vents; 2) eruptive fissures; 3) Etna volcanics; 4) Tertiary-Quaternary sedimentary basement and alluvial deposits; 5) Valle del Bove depression, and C. C. near the summit denotes the central crater. 
there should be some magnetized remnants of the plumbing system for the parasites. Chiarabba et al. [2004] studied the plumbing system of Etna with seismic tomography and presented distributions of seismic P wave-velocity; a high velocity zone was detected at shallower zone at the $S$ flank. The zone may be related to the conduits of the parasitic vents, therefore it may be reasonable to assume some solidified magma beneath the SE flank of Etna.

\subsection{Directionally radial distribution from the centers of} main volcanoes

On some polygenetic volcanoes, parasitic cones range in radial directions in chain and all chains are distributed in radial distribution, systematic overall. Such distributions of parasitic vents agree with the hypothetical assumption that the parasitic vents are distributed as a function of radial distance, as mentioned above. And furthermore, linear distribution along the slope of a volcano and circumferential distribution around the volcano axis, if any, are deemed as singular in the present assumption.

Two of very active and well-studied volcanoes in Japan, the adjacent Miyake and Ooshima volcanoes, the both belonging to the Izu-Mariana arc, shall be exemplified.

Miyake (775 $\mathrm{m}$ a.s.1.), the Seven Izu Islands: Miyake Island is located in the Pacific at about $180 \mathrm{~km}$ $\mathrm{S}$ of Tokyo and the rocks are basaltic. According to Isshiki [1960], its parasitic vents are distributed as shown in Figure 5.

On Miyake, we have historical records of 12 eruptions since 1469 A.D. and 11 of these eruptions were simultaneous at the summit and parasites; exceptional one was in 1983. Isshiki [1964] described the eruption modes of these eruptions. Almost all of the parasitic eruptions in the SE half of the island formed radial chains of vents along the flanks as shown in Figure 5. Many eruptions started at the tops of chains and migrated downward. Magma effusion rates were large at early stages of eruptions. On each chain, the vents are usually independent each other and are not linked by fissures. From these observations, we may assume that chains of parasitic vents derived from a single sub-conduit branched at shallow depths and resulted from shearing stresses acting in the radial direction and hydraulic pressure of fluidal magmas. Thus, on Miyake, a chain of parasitic vents is counted as one vent located at the starting point and is marked with a circle in Figure 5. The total number of the parasites amounts to 36 .

Density distribution of the parasites in relation to radial distance from the center of the volcano is shown in Figure 6 where the peak at $r=3 \mathrm{~km}$ is prominent.

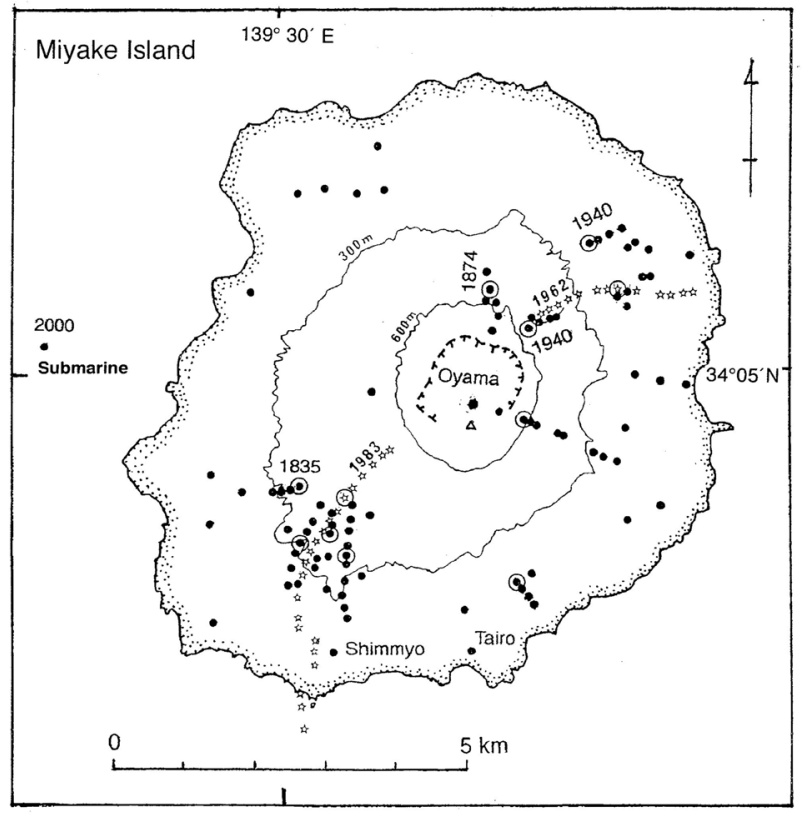

Figure 5. Distribution of parasitic vents on Miyake Island mainly according to Isshiki [1960], including the vents of the 1962 and 1983 eruptions. Chains of vents are assigned by the present author and double circles denote the first eruption vents of the chains. "Shimmyo" and "Tairo" in the south are prehistoric crater lakes. The summit topography is as of 1991 .

This group is mainly distributed around the contour of $300 \mathrm{~m}$ a.s.l. Prior to the 2000 summit eruption, a small submarine spout of juvenile ejecta emerged $1.8 \mathrm{~km} \mathrm{~W}$ from the shore of the island. A probable conduit to this eruption site shall be discussed in Section 3.3.

Ooshima (758 $\mathrm{m}$ a.s.1.), the Seven Izu Islands: Ooshima Island is located at a distance of about $110 \mathrm{~km}$ $S$ of Tokyo and its rocks are basaltic. The present active

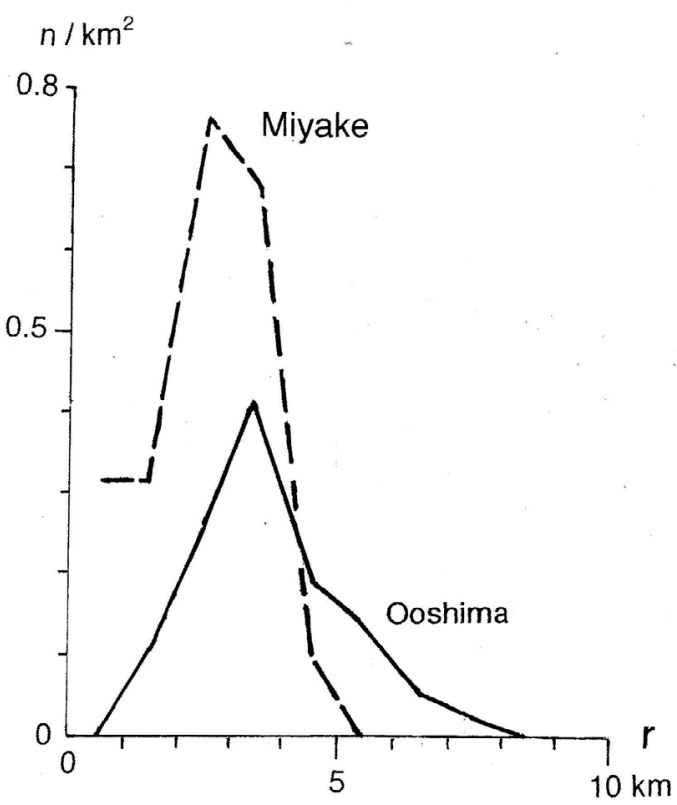

Figure 6. Spatial density distribution $\left(\mathrm{n} / \mathrm{km}^{2}\right)$ of parasitic vents on Miyake and Ooshima against radial distance from the central axes of respective volcanoes. 
cone within the summit caldera stands on the basement of younger Pliocene age. According to Nakamura [1961], distribution of the parasites on Ooshima Island is shown in Figure 7 where a chain of 4 conjoined points at the $\mathrm{E}$ slope is located on a volcano-tectonic fault. The vents within or near the summit caldera may be auxiliary to the main crater and are not counted as parasites. The eruption records of this volcano date back to 684 A.D. and of the 18 known eruptions, the 684 and 1421 eruptions are reported to have been parasitic eruptions. However, the details of both supposed parasitic eruptions remain doubtful. Therefore, in short, we have no solid proof of when parasitic eruptions may have occurred on Ooshima. The parasite chains shown in Figure 7 are identified only by geographical arrays of the vents because we have no data from their eruptive sequences. Nakamura [1961] proposed that the parasites on this volcano were mainly distributed along the long axis of the island. However, his proposal is doubtful due to the insufficient number of events, especially on the $\mathrm{E}$ and $\mathrm{W}$ sides of the island. We are not sure whether another parasites will be produced around there for many centuries in the future.

The present author concludes that the parasite distribution on Ooshima is uncertain because suitable examples of parasitic vents are scanty. As with Miyake, only the highest vent (circled) of a chain of vents is counted

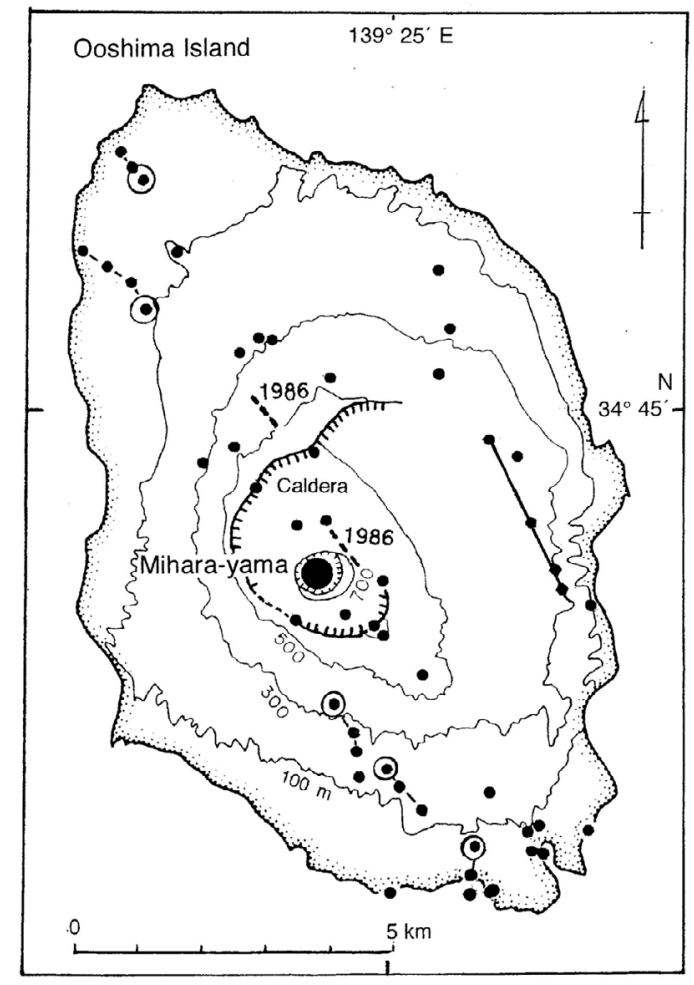

Figure 7. Distribution of the parasites on Ooshima Island after Nakamura [1961]. Double circles denote the probable first eruption vents of the chains of vents. The central cone within the summit caldera is called Mihara-yama. as a parasitic vent. Thus, parasitic vents on Ooshima Island amount to 32 in number. The density distribution of parasitic vents against radial distance is shown in Figure 6 where the peak at $r=3.5 \mathrm{~km}$ is prominent.

Similarity in the formation of parasites between Ooshima and Miyake: Nakamura [1977] proposed that the fracture zones along the long axis of Ooshima Island were produced mainly by regional stress rather than independently produced within the island by up-thrusting stresses of a magma reservoir. Against this idea, the present author assumes that parasitic vents on both Miyake and Ooshima, including chains of vents along the flanks, are statistically similarly distributed as a function of radial distances from the central axes as shown in Figure 6. One problem is determining whether a volcano body is a derivative of the crustal structure or a simple accretion on the Earth crust. If we adopt the former hypothesis, we need to explain why Miyake is not affected by regional stresses. The adjoining volcanoes, Miyake and Ooshima, are both composed of basaltic rocks and roughly of the same dimension. It is noticeable that their density distributions of parasitic vents (Figure 6) have peaks at similar radial distances, around $3 \mathrm{~km}$. This suggests that the parasitic cones on both the volcanoes mainly derive from a similar depth of about $4 \mathrm{~km}$ (cf. Section 3.1) beneath each volcano. The parasites of such shallow origin should be related to local stresses derived from magma reservoirs.

\subsection{Annular distribution centering at the axes of main} volcanoes

At present, the author can find one example of this type of distribution though the parasites on this volcano have formed roughly semi-annular distribution in the historical ages.

Usu (733 m a.s.1.), Hokkaido: it has a relatively large summit crater of about $2 \mathrm{~km}$ in diameter. Prehistoric basal lavas were basaltic and products of historical eruptions are all dacitic. Its topographic sketch map is shown in Figure 8. Historical documents of Usu date back to the 17th century. Parasitic mound $\mathrm{HM}$ is prehistoric. The 1769 and the 1853 summit eruptions formed lava domes Ko-Usu and Oo-Usu, respectively in the summit crater. These are probably directly connected to the main conduit, and are not parasitic domes: in future, we shall have to check their monogenetic activities.

On Usu, it is significant that all the parasitic vents are distributed roughly annularly along a contour line of $200 \mathrm{~m}$ a.s.l., in other words, on a circle of about 3 $\mathrm{km}$ in radius from the volcano axis. Also prehistoric mounds $\mathrm{HM}, \mathrm{S} 1, \mathrm{~S} 2$ and $\mathrm{S} 3$ are approximately located on the same contour. As discussed above, we know em- 


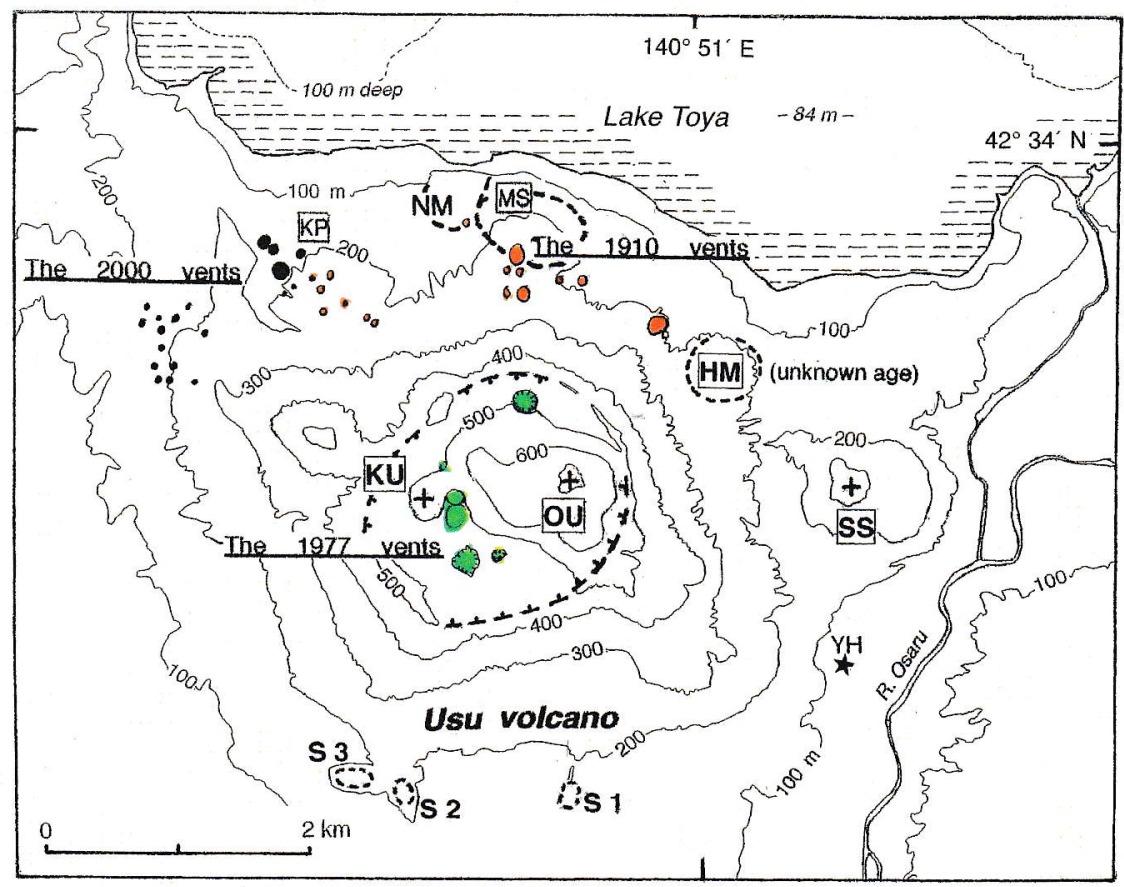

Figure 8. Usu volcano: Formation of parasitic domes ( $\boldsymbol{\uparrow}$ symbols) and mounds (broken lines). $\mathrm{KU}$ : the 1769 lava dome; $\sqrt{\mathrm{OU}}$ : the 1853 lava dome, red spots: the 1910 vents; $\mathrm{MS}$ and $\mathrm{KP}$ : the 1910 mounds; SS : the 1944 lava dome; YH: the 1944 mound; green spots in the summit crater: the 1977 vents; black spots in the NW foot: the 2000 vents; HM, S 1, S 2 and S 3: prehistoric mounds.

pirically that parasites are monogenetic. Anticipated future eruptions of Usu should occur at the summit, or otherwise at "parasite gap" around the volcano, probably along the contour of $200 \mathrm{~m}$ a.s.l. And as shall be discussed in Section 4.2, on some polygenetic volcanoes, parasitic eruptions occur sometimes simultaneously with the activities of summit craters. On the other hand, activities of main craters have not any effect on those of pre-existing parasites.

\subsection{Parasitic lava domes and mounds}

As a particular case of parasitic activities, parasitic lava domes and mounds afford us supplementary knowledge. They usually derive from dacitic or andesitic magmas and are here classified into two types according to their eruption sites: one is the formation of lava domes in main craters of volcanoes and the other are parasitic ones outside of main craters. Subsequent explosions inevitably destroy the former during future eruptions. After further eruption activity, a new lava dome shall regenerate at the same places: this is due to the fact that the main conduit remains open or active and directly connected to the magma reservoir. There are many examples of these two types of dome activity throughout the world. Here, to discuss characteristics of parasitic lava domes and mounds, those on Usu shall be exemplified.

Parasitic lava domes and mounds on Usu: all historical eruptions of Usu derived from dacitic magmas. Annular distribution of the parasitic vents on Usu was al- ready discussed in the previous Section. The four eruptions of Usu in the 20th century were observed at levels of those days.

The 1910 eruption burst at the $\mathrm{N}$ foot of the volcano (red rounds in Figure 8). The first vent opened at $\mathrm{KP}$ and thereafter more than 40 vents, large and small in diameter, were formed randomly in over a period of 13 days roughly along a contour of $200 \mathrm{~m}$ a.s.l. All the vents were formed in phreatic explosions. Among them, a parasitic mound of about $100 \mathrm{~m}$ in relative height (MS in Figure 8) was once called "cryptodome" which was defined as a volcanic cone underlain by a lava mass. Tanaka and Yokoyama [2013] studied the subsurface structure of MS hill with muography and obtained a density image of the subsurface part. It verifies that the hill is not a cryptodome but a mound that was pushed up as a tubular table. The top of the magma remains at a depth of about $60 \mathrm{~m}$.

The 1944 eruption began in early 1944, and the first small uplift of about $23 \mathrm{~m}$ in relative height appeared at spot "YH" at the SE base of the volcano (Figure 8), and after one month, another magma branched from the main conduit at a depth of about $3 \mathrm{~km}$ and reached a cornfield about $2 \mathrm{~km}$ distant northward from "YH" with accompanying earthquakes and explosions, and forming a mound. There, dacitic magma extruded about $110 \mathrm{~m}$ high above the mound and grew about 300 $\mathrm{m}$ high above the cornfield in 22 months: this is lava dome SS (Showa-Shinzan). Tanaka and Yokoyama [2008] studied the structure of SS lava dome with 
muography and proved that the top part of the dome is of bulbous shape and the upper part of the conduit is about $50 \mathrm{~m}$ in diameter. After the magma elevated to its highest level, it grew laterally forming a bulbous shape. It is noticeable that this branch of dacitic magma had reached the dome site during its fluidal condition.

The lava domes formed at the base of Usu in the 1910 and 1944 eruptions are monogenetic because the vents and sub-conduits of these lava domes already solidified and not directly connected with the main conduit. The 1944 lava dome to be mentioned in Section 4.1 exemplifies this case.

The 1977 summit eruption: the eruption took place within the summit crater (Figure 8). An explosion first burst near the Ko-Usu (small Usu) lava dome KU formed in 1769 and its relative height reached $109 \mathrm{~m}$ as of 1977. There was little damage from the explosions but, accordingly as the eruption developed, the lava dome had subsided about $52 \mathrm{~m}$ as a whole during 2 years probably a consequence of new magma scraping the root of the dome. Oo-Usu (big Usu) lava dome $\mathrm{OU}$ was formed in 1853 and its relative height was $227 \mathrm{~m}$ as of 1977. It was partly damaged by the 1977 explosions but apparently elevated about $6 \mathrm{~m}$ due to a tilt of the summit portion caused by magmatic force applied to the northern half of the summit part at approximately 11 degrees in arc after the explosive activities [Yokoyama and Seino 2000]. Both $\mathrm{OU}$ and $\mathrm{KU}$ are within the main crater, and the latter scarcely escaped from destruction amid the 1977 eruption. If they were destroyed, new domes would have replaced them over time: they are not monogenetic within the summit crater.

The 2000 eruption was phreatic and phreatomagmatic with outbursts at more than 60 vents, tiny and small in diameter, around the NW base roughly along a contour of $200 \mathrm{~m}$ a.s.l. (black spots in Figure 8). The vent areas of both eruptions in 1910 and 2000 did not overlap in the surroundings of the $\mathrm{KP}$ hill. This means that conduits of parasitic vents usually would not be reoccupied; i.e. parasitic volcanisms are monogenetic.

\section{Formation of parasitic vents and their character- istics}

In volcanic processes of polygenetic volcanoes, summit craters mainly act to discharge magmatic material and energy, forming volcano edifices. The summit craters or main conduits are originally created by the upward magmatic forces or eruptions derived from magma reservoirs. When magma is activated, it has possibility of following one of three patterns to reach the surface: an eruption at the main crater only, simultaneous eruption at the main crater and new parasitic vents, and parasitic eruption only. The possibility de- pends on the balance between the strength of the local ground and magmatic forces at each origin. Usually it is difficult to distinguish the patterns of prehistoric eruptions.

Corazzato and Tibaldi [2006] discussed magmafeeding fractures to explain characteristics of parasitic cones and led the models of pre-existing volcano-tectonic structure and propagating magma-filled cracks exemplifying the parasitic cones on Etna. The present author will discuss the origin of the fractures from the standpoint of material mechanics in this section.

As for configurations of magma conduits, Poland et al. [2008] modeled a radial dike emplacement based on observations from Summer Coon volcano, Colorado. They showed two schematic cross-sections of possible radial dike development specific to that volcano: one is planar and the other is tubular. They favored the latter because the large area caught between the dike and country rocks would cause the intrusion magma to solidify before it reaches the surface. In the following part, we assume a deep magma reservoir or its shallow derivative to be the origin of magmatic activities, and main craters of polygenetic volcanoes are fed through a tubular main conduit. Necessarily our discussion on formations of parasites shall follow the supposition that tubular dikes create parasitic vents.

\subsection{Shear fracture model for the formation of parasitic} vents

Generally formations of parasites are related to upward magma movements originated from magma reservoirs, directly or indirectly. Here, to interpret the formation of parasites, we adopt a simple mechanical model that should be related to structure and strength of main volcano edifices and origin of magmatic forces. Actual volcano structure is not always uniform and there may be some week points. Even if volcano edifices are under such condition, the results of a modeling may furnish hints to discussion of parasite formation. On the other hand, another model may be possible; for example, propagation of laterally extensive dikes was assumed to interpret formations of parasitic vents in the 1912 eruption of Novarupta (cf. Section 3.3) and the 1996 eruption of Karymsky [Fedotov 1998]. As another example, in the 1970 eruption of Hekla (Thorarinsson [1970] and Section 3.2), a vertical conduit directly connected to a magma reservoir was adopted to explain magma supplies to parasitic vents.

Shear fracture model: This was already discussed by De la Cruz-Reyna and Yokoyama [2011], Yokoyama $[2013,2014]$, and so here, shall be briefly summarized. Magmatic forces act either at a magma reservoir or at the top of an ascending magma column, and are mod- 


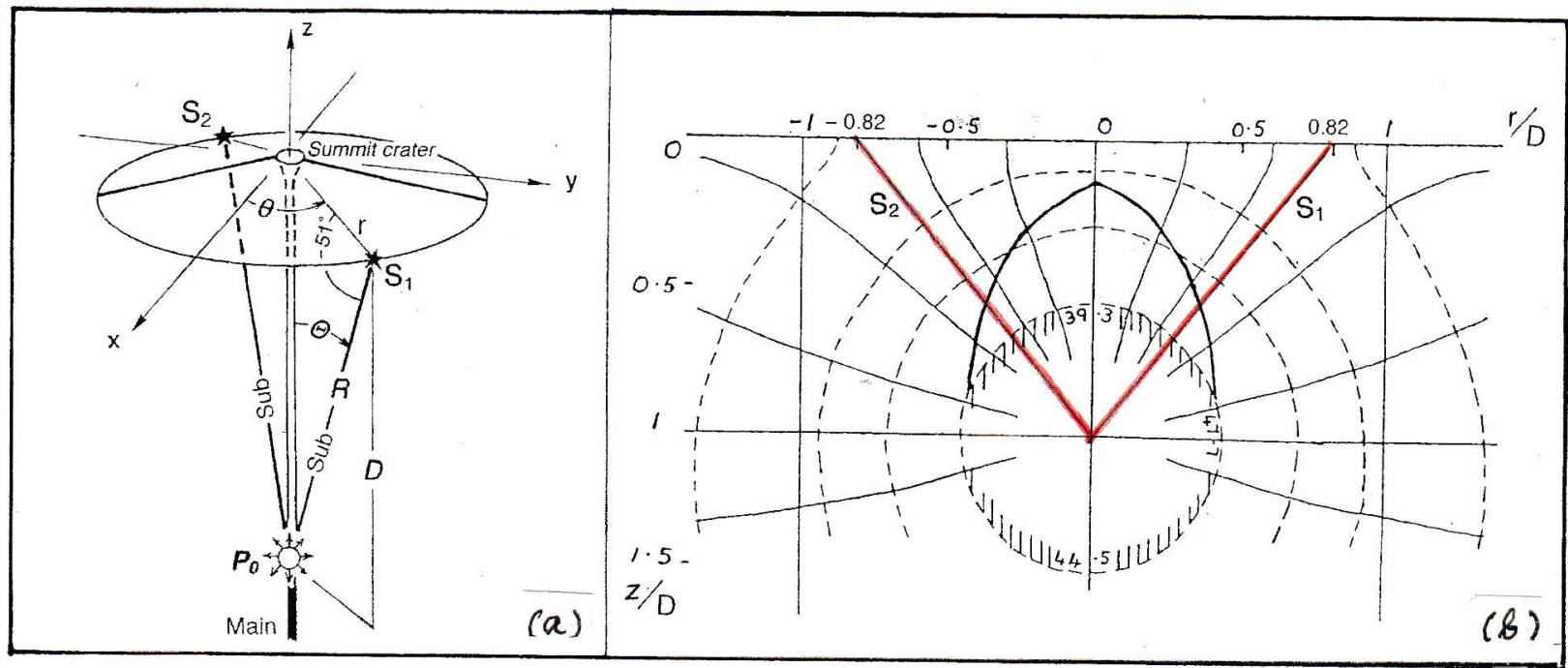

Figure 9. (a) Shear fracture model for formation of parasitic vents due to a dilatational source $P_{0} . S_{1}$ and $S_{2}$ denote twin parasites. "Main" and "Sub" denote the main and sub-conduit, respectively. (b) Broken lines show isostatic surfaces produced by point dilatation after Anderson [1936, fig. 8]. Opening fractures would follow the fine firm lines. $S_{1}$ and $S_{2}$ are added by the present author.

eled upon dilatational pressure. We adopt polar coordinates $(R, \Phi, \Theta)$ with the origin at a pressure source.

According as a volcano is activated, magmatic pressure is exerted towards the pre-existing main crater through the main conduit, and if the pressure overcomes the yielding strength of cap-rocks at its crater, an explosion should be triggered; this is usual with polygenetic volcanoes and interpretable by the maximum stress theory. In the following section, we discuss formations of parasitic vents by applying the criteria of fracture mechanics, specifically the maximum shear stress theory. At a certain point on the flat surface of a volcano, both pressure and shear exert stresses on the structure. If either of them reaches the yielding strength, the corresponding part of the volcano should fracture. Usually shearing strength of rocks is much smaller than compressive one. Here we adopt plane polar coordinates $(r, \theta)$ at the surface and consider the effects of shear stress: the maximum shear stress is equal to a half of the horizontal differential stress and is represented as:

$$
1 / 2\left(\sigma_{\mathrm{rr}}-\sigma_{\theta \theta}\right)
$$

where $\sigma_{\mathrm{rT}}$ and $\sigma_{\theta \theta}$ denote the principal stresses. The maximum shear stress occurs across a plane whose normal bisects the angle between the greatest and least principal stresses.

After some calculations [De la Cruz-Reyna and Yokoyama 2011, Yokoyama 2013, Yokoyama 2014], we get the value of the term (1), positive or negative maximum at

$$
r= \pm 0.82 D, \text { or } D=1.22 r
$$

In other words, the medium receives the maximum horizontal differential stress at a radial distance $r= \pm 0.82 \mathrm{D}$, or where the dip angle of the pressure source from the fracture point at the surface is $51^{\circ}$. Consequently, shear fracture takes place there in the radial direction on the surface or along the slope. Theoretically we expect the maximum horizontal differential stress to be present at two points, $r= \pm 0.82 \mathrm{D}$, or on symmetric sides of volcanoes. The possibility of a fracturing point pair such as this may depend on particular conditions on each volcano those are not wholly clear. When a parasitic vent is formed, the other symmetric fracturing point is probably not present due to stress concentration at the former. Furthermore, the majority of volcanoes including Fuji and Etna are not uniform in structure and hence, the above results are not always actualized. In fact, formation of twin parasites has been rarely observed in historical records. Some of the rare examples shall be discussed in Section 3.2.

Equation (2) is schematically expressed in Figure 9a; the magma rises from the depths to origin $P_{0}$ through the main conduit and acts as a pressure source. Pressure $P_{0}$ exerts compression towards the summit inducing stress accumulation there and simultaneously $P_{0}$ exerts shear stresses at $S_{1}$ and $S_{2}$. Whether magma discharges through the main crater as a result of the maximum strain or at the parasitic fractures by the maximum shear strain depends on the condition of the existing main crater and strength of the medium concerned, or should be determined by the balance between these factors. Thus, rock strength plays an important role in the above determination. Compressive rock-strength is roughly on order of $100 \mathrm{MPa}$ and shearing rock-strength roughly on order of $10 \mathrm{MPa}$ [Jaeger 1964], but these 
two kinds of strengths are very variable according to the conditions. There must be a delicate balance between upward compressive force against the strong compressive strength and shearing force against the weak shearing strength. When shear fracture overcomes compressive one, the magma proceeds towards the surface at an elevation angle of $51^{\circ}$.

\subsection{Examples of twin parasitic vents}

Interpretation of twin parasites verifies the validity of the above shear fractural model. However, this model depends on the assumptive uniform structure of volcano edifices. In addition, on many volcanoes, if either of twin fractures is formed, shearing stress may concentrate at the first fracture point and the second one does not follow. The origin of the stress concentration is unknown, possibly may derive from host rock properties, regional stress field, and so on. On some volcanoes, parasitic eruptions occur simultaneously at two opposite sides roughly symmetrically with respect to the central axis of a volcano. Examples of this phenomenon are not well known since prehistoric twin cones can't always be recognized geologically. A rare instance is on Sakurajima volcano where the last three largest eruptions have produced twin parasitic vents. In the following section, these three Sakurajima eruptions shall first be described and then three other examples of twin vents at Fogo, Hekla and Tyatya shall be briefly commented upon:

Sakurajima (1117 $\mathrm{m}$ a.s.1.), Kyusyu: this volcano is

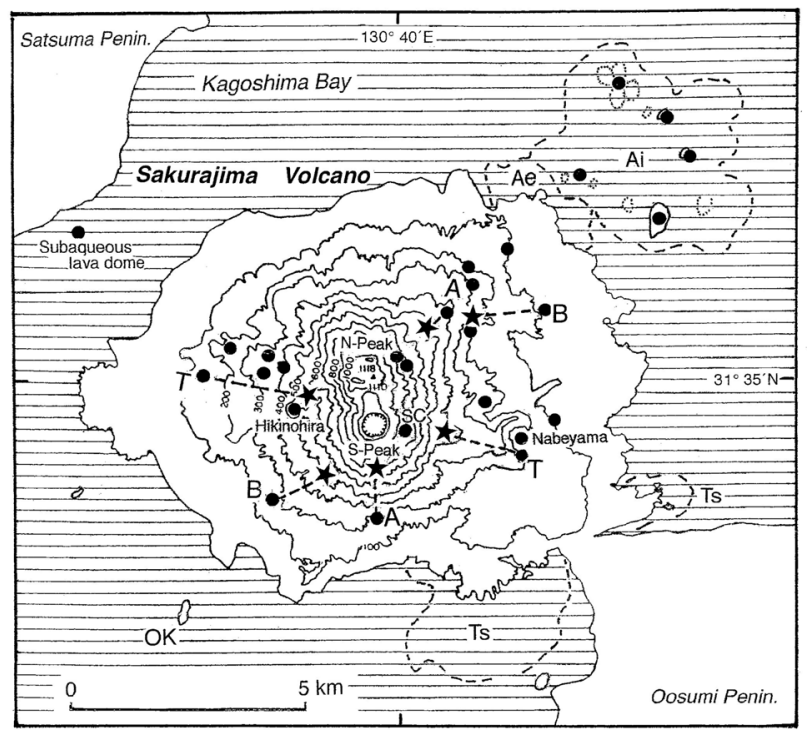

Figure 10. Distribution of parasitic vents on Sakurajima volcano in the historical record after Kobayashi [1988]. Twin parasitic vents were formed in the 1476, 1779 and 1914 eruptions marked by B, A and T, respectively. Islets Ai were formed in the 1779 eruption. The parts marked with Ts are the submarine lava flows from the 1914 vents. SC denotes the 1946 crater. a small island composed of andesitic rocks measuring about $10 \mathrm{~km}$ in diameter, and the age of this volcano is about $10^{4} \mathrm{yr}$. B.P. Some of the old parasitic vents have been totally covered with the ejecta of the later eruptions. After Yamaguchi [1975] and Kobayashi [1988] who studied geology of this volcano, distribution of the parasites on Sakurajima is shown in Figure 10.

The 1471-1476 eruption: in November 1471, parasitic eruptions started from Point $\star$ and reached B on the NE flank of the North Peak, and issued lava flows. In October 1476, similarly the twin vents ranged from Point $\star$ to B on the SW flank of the South Peak, and issued another lava flows. Each vent was a chain of several small vents along the slopes. It is noticeable that the twin vents were completed in 5 years after the first outburst: the duration of 5 years may be a single cycle of this volcanic activity.

The 1779 eruption: the twin vents were completed in 2 hours and the lava-flow activities continued for 2 weeks. At the last stage of this eruption, submarine eruptions occurred at the NE off Sakurajima Island ("Ai" in Figure 10), but these are located at a further distance from the center of the volcano than the twins on the island and their branch may be deeper. The counterpart of "Ai" topographically corresponds to an island $(\mathrm{OK})$ at $\mathrm{SW}$ off Sakurajima Island that is located on the rim of Aira caldera, and geologically different from Sakurajima Island.

The 1914 eruption: this eruption was more precisely observed than the previous two, and provides us with important information on twin parasites.

[16:30, Jan. 9]: the first precursory earthquake occurred. [08:00, Jan. 12]: a column of white smoke abruptly shot up from the top of South Peak, the main summit crater (probably it was before completion of the parasitic conduit). [10:00]: explosion began on the W flank (the western sub-conduit was completed). [10:10]: explosion occurred on the E flank (both the sub-conduit systems were completed quasi simultaneously). The parasitic eruptions started at the opposite sides of the volcano, both from Point $\star$ and to T. [18:28]: an earthquake of M 7.1 occurred. Probably it was not directly related to twin parasites but to magma movements in a large scale because both the vents were already opened. [20:00 approx. Jan. 13]: lavas began to flow out from both the vents. Judging from the above sequences, we may say that formation of twin magma paths needed about 3 days and didn't consume much energy in comparison with the succeeding eruptions.

As for future twin eruptions on Sakurajima, we may get a rough idea of probable eruption spots, "parasite gaps" in Figure 10. The three eruptions of twin parasites since the 15th century suggest that Sakurajima volcano 
actually has rather uniform structure and the upward magmatic forces had been kept constant for these periods. This may be an exceptional case in its history.

Fogo (2829 $\mathrm{m}$ a.s.1.), the Cape Verde Islands (the 1951 eruption): this volcano is on the island of Fogo measuring about $24 \mathrm{~km}$ in diameter and its central cone is $2829 \mathrm{~m}$ a.s.l.: about $6 \mathrm{~km}$ high above sea bottom. After Machado [1962], the topography with lava flows

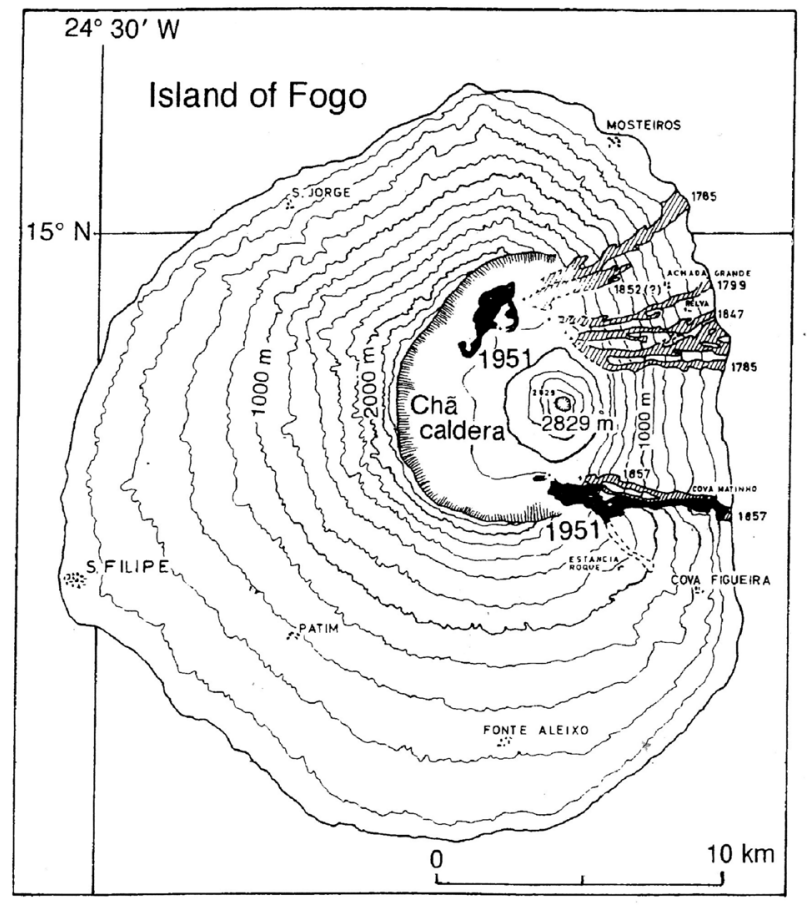

Figure 11. Twin parasitic vents formed in the 1951 eruption of Fogo volcano after Machado [1962].

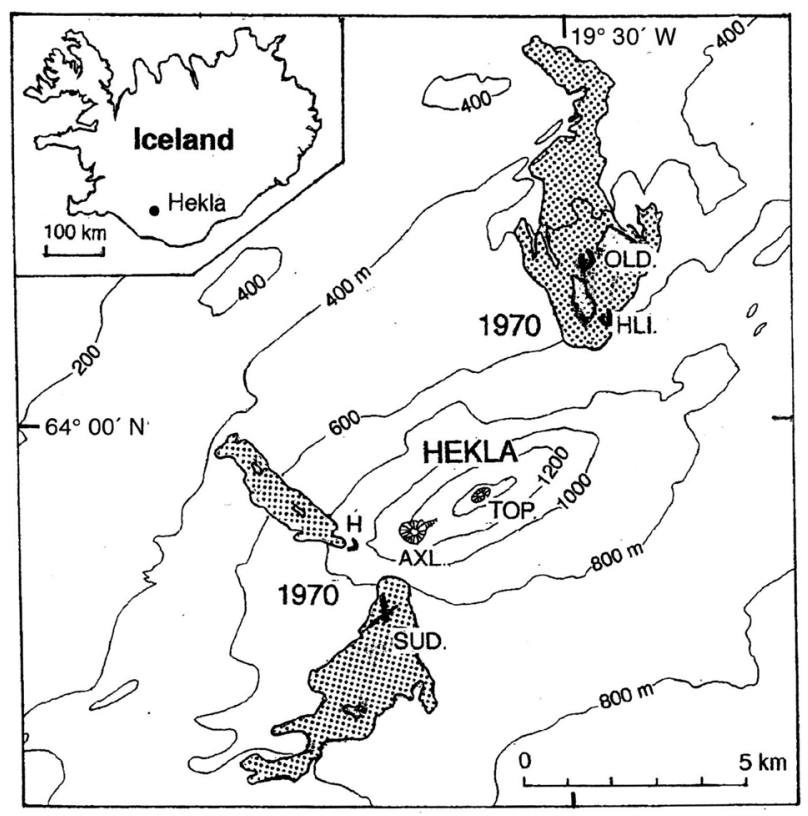

Figure 12. The 1970 eruption of Hekla volcano (after Thorarinsson and Sigvaldason [1972]); HLI and H: the 1947 vents; OLD: Ölduígagr lava; Sud: Sudurgígar lava; TOP and AXL: Summit craters. is shown in Figure 11. Twin parasitic vents were formed at the caldera bottom during June to August 1951, and issued basaltic lava flows. Both vents are $3 \sim 4 \mathrm{~km}$ distant from the central cone. This may be the first formation of twin vents on this volcano judging from the distribution of lava flows. Later, in 1995, two fissures erupted on the SW flank of the central cone, not in twin and issued lava of about $3 \times 10^{6} \mathrm{~m}^{3}$.

Hekla (1491 m a.s.1.), Iceland (the 1970 eruption): according to Thorarinsson and Sigvaldason [1972], Hekla erupted in 1970 at opposite sides of the summit (Figure 12); the eruptions occurred at the both sites simultaneously within 70 minutes and ejected tephras, and basalt lavas. In the figure, only the 1970 lava flows are shown. The vents of the eruptions were located at the ridge, about $3 \mathrm{~km} \mathrm{SW}$ and $4 \mathrm{~km} \mathrm{NE}$ each from the summit crater. The eruption process suggests that these two are possibly twin vents. If we employ the shear fracture model, the depths of branches from the main conduit of Hekla are estimated to be about $4.3 \mathrm{~km}$ on an average from the relation $(D=1.2 r)$. On the other hand, Thorarinsson [1970] interpreted twin shoulder (ridge) eruptions as to have been deep-fed separately from deeper magma zones unlike the magma reservoir of Hekla: petrologically, the former is basic and the latter is acidic. His interpretation needs two deep-fed conduits. We may modify Thorarinsson's model to apply the shear fracture model: a magma conduit fed from the deep magma zone reaches at a depth of about $4.3 \mathrm{~km}$

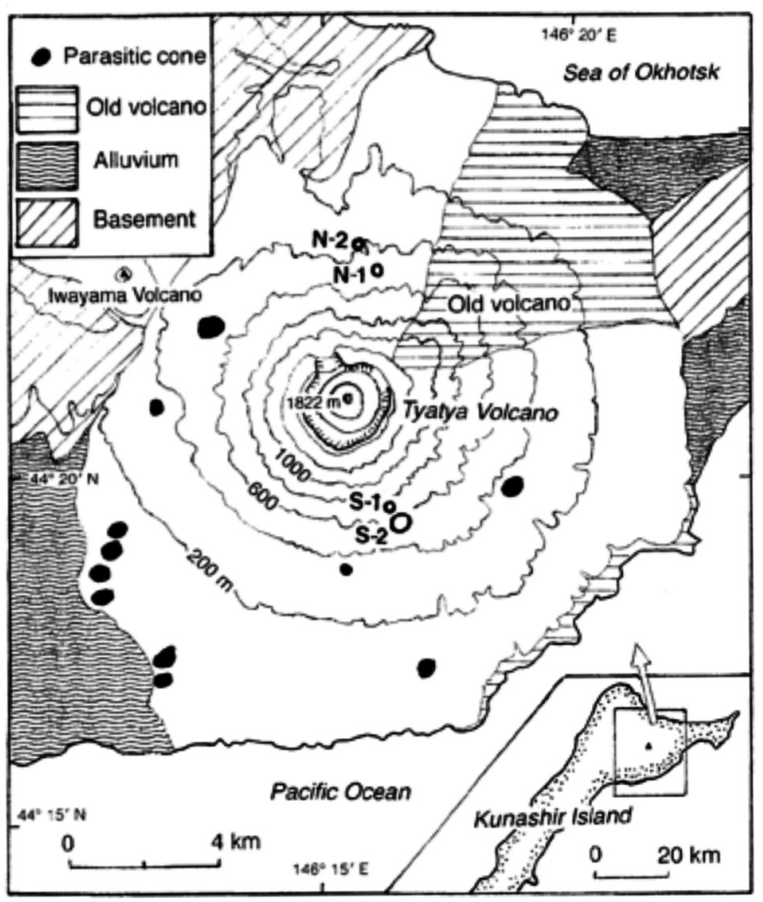

Figure 13. A geological sketch map of Tyatya volcano (Nakagawa et al. [2002], simplified). N-1 and N-2 parasites erupted on 14 July, and S-1 and S-2 parasites did on 28 July, both of 1973. 
and branches out into twin sub-conduits for parasites under particular condition discussed above. Anyway, the shear fracture model is another interpretation of parasites compared to Thorarinsson's interpretation.

Tyatya (1772 m a.s.1.), Kunashir Island, Kuril (the 1973 eruption): it is located at the E end of Kunashir Island, facing the sea at the $\mathrm{N}$ and $\mathrm{S}$ sides and measuring about $18 \mathrm{~km}$ in basal diameter and $1822 \mathrm{~m}$ a.s.l. A geological sketch map of Tyatya volcano after Nakagawa et al. [2002, fig. 2, simplified] is shown in Figure 13. According to them, there are 14 parasitic p. 22cones at the flank of the volcano that had intermittent magmatic eruptions more than 1000 years ago. Before the 20th century, the eruptions occurred mainly at the summit central cone. Historically recorded eruptions of Tyatya volcano took place during 1812 . These activities occurred mainly at the central cone. The parasitic eruptions in 1973 occurred about 150 years after the last major eruption of the central cone, effusing lava flows and accompanied with scoria fallout.

On June 17, 1973, a tectonic earthquake of M 7.4 occurred off Nemuro Peninsula, Hokkaido. The epicentral distance from Tyatya volcano was about 140 $\mathrm{km}$, and one of the aftershocks of M 7.1 followed on June 24. The eruption of Tyatya occurred first on July 14 on the $\mathrm{N}$ flank and the second eruption (possibly on July 16) was concentrated on the S flank. The 1973 eruption of Tyatya was the largest eruption during the 20 th century in the SW Kuril arc. Nakagawa et al. [2002] concluded, from petrographical study of the ejecta, that the magma feeding system of the 1973 eruption must be different from that of the central cone, and that magma ascended rapidly without any stagnation at a shallow level during the 1973 activity.

In other words, the maximum shear stress theory suggests that twin parasites on polygenetic volcanoes are possible. However, it also raises the question of what factors are required to classify either formation of twin or single parasites.

3.3. Depths of parasitic branches or pressure sources adopted in the maximum shear stress theory and their relation to volcano structures

Spatial distributions of parasites on Fuji, Etna, Usu, Miyake, Ooshima and Sakurajima volcanoes with some mention of some twin parasites are focused upon in the previous chapters. The shear fracture model deduced from a dilatational source proved effective to interpret formation of twin parasites. However, when this model is partially disturbed by some factors such as complicated geological structure or stress concentration due to magma pressure at weak points in volcano body, the model may fail to produce twin parasites and instead produce only a single vent. Originally, single parasitic conduits may have possibly been formed by another factor such as a pre-existing crevice or propagating magma-filled cracks. In this section, the depths of parasitic branches present in some volcanoes shall be discussed tentatively assuming the maximum shear stress models.

The shear fracture model gives the relation $(D=$ $1.2 r$ ) by which we can assume probable depths of the parasitic branches of main conduits or the pressure sources. Here any relations between branch depths and volcano structure shall be conjectured for the abovementioned volcanoes:

Sakurajima (1117 m a.s.1.): though we have no exact knowledge of deeper structure of this volcano, it is known that "North Peak" (Figure 10) is underlain by an old edifice. The recent three largest eruptions since the 15th century all involved explosions forming the twin parasitic vents which are located at radial distance $r=$ $2 \mathrm{~km}$ on the average from the center of the volcano in Figure 10, and hereby their branch points $D=2.4 \mathrm{~km}$. According to Iguchi et al. [2013], the hypocenters of the volcanic A-type earthquakes which originated from shearing fractures of rocks are located at roughly $2 \sim 4 \mathrm{~km}$ below the Sakurajima summit crater. The above branch depth may correlate with the origin of these earthquakes. The magma reservoir under Sakurajima has not been directly related to branching of lateral conduits. And the three times formations of twin parasites may suggest that the abovementioned structure beneath "North Peak" is too shallow to effect the formations.

Usu (733 $\mathrm{m}$ a.s.l.): originally Usu has many parasites in an annular distribution; overall parasitic vents, including those formed in 1910, 1944, 2000 and prehistoric ages, are located at about $2.5 \mathrm{~km}$ distance from the center of the volcano (Figure 8 ) and are distributed roughly on the same altitude (about $200 \mathrm{~m}$ a.s.l.). According to Equation (2), the depth of the branch point from the main conduit is approximately $3.0 \mathrm{~km}$ beneath the volcano. Namely, magmas repeatedly branched from the central conduit at roughly the same point, but could not take the same path to the surface. Yokoyama and Seino [2000] studied the focal depths of the precursory earthquakes of the 1944 and 1977 eruptions, and concluded that starting depths of the Usu magma for the eruptions were around $5 \mathrm{~km}$ beneath the volcano. Thus we may conjecture that the Usu magma would branch laterally at a certain depth halfway to the summit by employing assumptive pressure source models.

Fuji (3776 $\mathrm{m}$ a.s.1.): radial distances $r=1 \sim 7 \mathrm{~km}$ are widely predominant in density of parasites and hence, the depths of parasitic branches range roughly $D=$ $1.2 \sim 8.5 \mathrm{~km}$. $\mathrm{H}$ crater near the summit branches from 
the main conduit at a shallow depth, $2 \sim 3 \mathrm{~km}$, within the mountain body where the material may be heterogeneous. The parasitic conduit of $\mathrm{N}$ crater branches at a depth of about $13 \mathrm{~km}$. As for such depths, Ukawa [2007] observed deep-low-frequency (DLF) earthquakes at the region $8 \sim 20 \mathrm{~km}$ deep beneath the volcano during the period April $1995 \sim$ December 2003: the depth $13 \mathrm{~km}$ coincides with the focal region. He interprets the DLF earthquakes as being related to magma movements.

Etna (3343 m a.s.1.): judging from the radial distribution of parasitic vents (Figure 3), there are two area of concentration, being $r=5.5$ and $13.5 \mathrm{~km}$; the former is grouped into three directions (NE, $\mathrm{W}$ and $\mathrm{S}$ around the summit) and the corresponding branch depths are about $6 \sim 7 \mathrm{~km}$. The latter is another group on the SE flank and their parasitic branches are about $16 \mathrm{~km}$ deep along the main conduit and several magma sub-branches cluster under the area forming magma intrusions as detected by geomagnetic anomalies (cf. Section 2.1).

Miyake (775 $\mathrm{m}$ a.s.1.): the parasitic vents distributed with the highest density around the radial distance of $r=2.5 \sim 3.5 \mathrm{~km}$ (Figure 6), with branch depths estimated at $3 \sim 4.3 \mathrm{~km}$. On the other hand, in the 2000 eruption of this volcano, the summit crater transformed to a caldera during gravitational collapses: Furuya et al. [2003] explained the collapse by indicating a deflation beneath the volcano discovered whilst observing simultaneous gravity changes on the volcano; they successfully deduced that the depth of the deflation was $5.3 \pm 0.45 \mathrm{~km}$. This depth was not appreciably different from the above estimates of the branch depths.

Ooshima (758 m a.s.1.): Mikada [1994] applied tomographic methods using seismic waves to Ooshima volcano, and detected scattering bodies at depths of about 5 and $8 \sim 10 \mathrm{~km}$ beneath the caldera. The deepest ones may be a magma reservoir. In the spatial density distribution of the parasites (Figure 6), it is prominent at $r=3.5 \mathrm{~km}(D=4.3 \mathrm{~km})$ roughly corresponding to a small seismic scatter at $5 \mathrm{~km}$ depth. The parasitic branches may possibly be located at a volcano-tectonic zone such as this.

In brief, if we adopt the maximum shear stress model, branches of parasitic conduits or pressure origins may all be located in tectonically active volcanic zones beneath volcanoes causatively or accidentally. Strictly speaking, their substance is not totally settled.

Application of the shear fracture model to the $1912 \mathrm{No}$ varupta dome and the 2000 submarine eruption off Miyake Island:

Novarupta (841 m a.s.l.), Alaska: according to Hildreth [1983], in 1912, Novarupta erupted magma of about $15 \mathrm{~km}^{3}$ in volume, eventually backfilling a flaring funnel-shaped vent with ejecta and forming a lava dome. Almost simultaneously, a caldera collapsed at the summit of Katmai, $10 \mathrm{~km}$ E of Novarupta. Hildreth and Fierstein [2000], referring to petrological discussions, proposed that magma was transported laterally from the Katmai reservoir to the Novarupta vent. Also Eichelberger and Izbekov [2000] made the assumption that magma was supplied to the shallow reservoir through planar dikes from the depths. With the supposition that $\mathrm{SiO}_{2}$ of Novarupta lava dome ranges $65 \sim 77 \%$ after Hildreth [1983], viscosity of the magma would exponentially increase according as the temperature declines. Hence, it must be difficult for the viscous magma to move laterally over a distance of $10 \mathrm{~km}$, being pushed by hydraulic magmatic pressure. The assumption of this planar dyke provides more challenging conditions than that of tubular one. An alternative and rather speculative interpretation may be possible by using the shear fracture model. In that case we infer that the sub-conduit of Novarupta branched from the magma reservoir of Katmai at a depth of about $12 \mathrm{~km}$ $(D=1.2 r)$. That may coincide in all likelihood with a part of the magma reservoirs of which depths were determined by seismic observations as $10 \sim 30 \mathrm{~km}$ beneath Katmai [Kubota and Berg 1967]. Thus, the conduits of Novarupta may have branched from the magma reservoir of Katmai. However, Hildreth and Fierstein [2000] assumed the Katmai magma reservoir directly related to the 1912 eruption at a depth of around $4 \mathrm{~km}$ from their synthetic studies, being much shallower than a branch point assumed by the present model. To conclude, we have two extreme hypotheses about magma movement in the 1912 eruption of Katmai.

Miyake: prior to its 2000 eruption, a small submarine spout of juvenile ejecta occurred at $1.8 \mathrm{~km} \mathrm{~W}$ off the island shore [Kaneko et al. 2005]. The spout point was $6.0 \mathrm{~km} \mathrm{~W}$ from the central crater. This parasitic activity was so small that seismometers on the island could not detect any seismic signals directly related to the spout. If we assume that this spout was transferred through a sub-conduit branched from the main conduit, the depth of the branch would be $7.3 \mathrm{~km}$ according to Equation $(D=1.2 r)$. Such an oblique tubular vent is more probable than a planar dike considering that magmas reach the surface more easily by the former.

\section{Some characteristics of parasitic eruptions}

We tried to interpret characteristics of parasitic volcanisms applying the shear fracture model in the above discussions but we know there remain a few characteristics of parasitic volcanisms not explained by this model such as individuality of parasitic vents and variable relationship between eruptions of main craters 


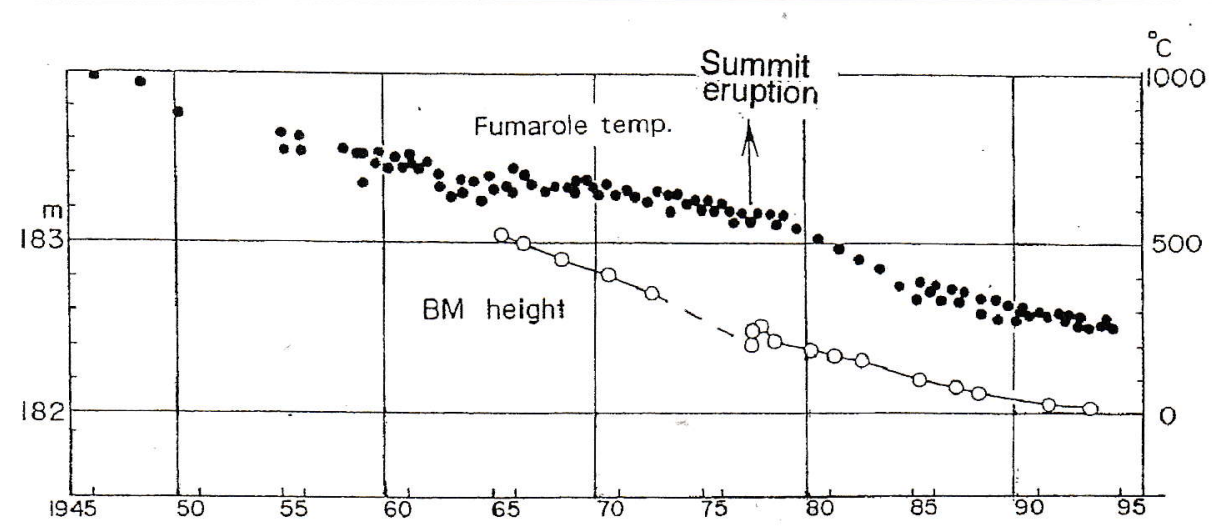

Figure 14. Usu volcano: influences of the 1977 summit eruption on the activities of the 1944 lava dome SS. Black circles: Temperature of a fumarole on the lava dome by the right-hand ordinate: Hollow circles: Height of a benchmark on the lava dome by the left-hand ordinate.

and parasitic vents, both these having been partly observed during our short history.

\subsection{Parasitic activities are usually monogenetic}

We know empirically that parasitic volcanoes are monogenetic. However, to apply this theorem in practice, we have to study these structures over a much longer period of time. On the other hand, we may interpret the theorem as follows: parasitic conduits are originally formed by cracks and are thinner than main conduits. After the branch conduit discontinues feeding a parasite, it would facilitate solidification of magma. Furthermore, around the branch point of the parasitic conduit, magma intrusions may mechanically strengthen the surrounding ground due to their "piling effects". This would block the new parasitic conduits from taking the same route to the surface and so instead these conduits would utilize a parasite-free point (the "parasite gap"). This may be a plausible reason for parasitic volcanoes erupting only during a cycle of activity. In the following instance, a model for parasite formation shall be assumed on the basis of relationships with the central conduits of volcanoes. The model is not unique because each volcano should have its own structure and geological compositions, and magma may be driven upward by its buoyancy and tectonic forces to form parasites.

Another conception for formation of parasites may be possible, such as that parasitic conduits directly derive from magma reservoirs or magma zones, independently on main conduits. This was once proposed by Thorarinsson [1970] when he interpreted the 1970 Hekla eruption (cf. Section 3.2). This would hold true to monogenetic volcanism in general according to De la Cruz-Reyna and Yokoyama [2011].

After the parasitic vent's cycle of activity ends, usually the vent does not recover. Here, some behaviors of the parasitic lava dome SS (Figure 8) formed by the 1944 Usu eruption shall be exemplified with relation to the activity of the main volcano: Yokoyama and Seino
[2000] monitored the secular changes in altitude of a benchmark and temperature of a fumarole, both being on the dome, as shown in Figure 14. The gradual subsidence of the benchmark is due to ground compaction by the self-weight and no supply of any material. Also the temperature of the fumarole smoothly declined with time to about $100^{\circ} \mathrm{C}$ as of 2014 , without any supply of heat energy. In 1977, the volcano erupted violently forming several craters within the summit crater. The distance between the main cone and the lava dome was about $3 \mathrm{~km}$ in Figure 8 but the activities of the lava dome were not influenced by this eruption. This means that the conduit of the lava dome had become closed from the main conduit by 1977. In short, parasitic vents would become totally monogenetic after the cycles of their activities finish.

Parasitic vents located near the main craters: usually main craters would continue their activities as far as the magmas are active. During the active periods, parasitic vents occasionally are formed around the summit craters or calderas, for instance, in the 1946 eruption of Sakurajima (SC in Figure 10) and the 2001 eruption of Etna [Calvari and Pinkerton 2004]. A problem is how we can distinguish parasitic vents near the summits. We may distinguish these parasitic vents by examining whether they are monogenetic or not: if they are not monogenetic, they are not parasitic but originally auxiliary to the main craters.

4.2. Parasitic eruptions occurring simultaneously with activities of summit craters

Parasitic cones are usually formed on large polygenetic volcanoes and are fed through parental conduits of the volcanoes. Parasitic activities are monogenetic as far as we have observed in the historical record and display various spatial and sequential patterns on parental volcanoes as discussed above. On some volcanoes, parasitic eruptions are often simultaneous with summit eruptions, and on other volcanoes, such con- 


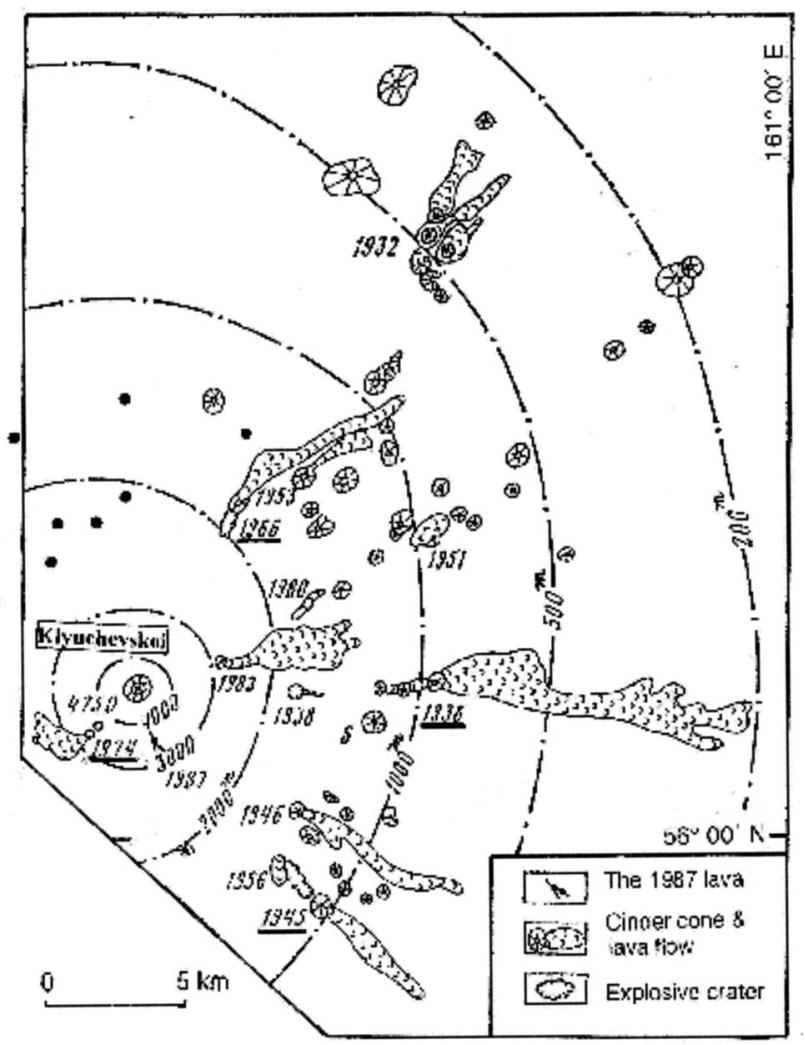

Figure 15. Distribution of parasitic vents on Klyuchevskoi volcano after Fedotov et al. [1990]. Chain lines are height contours in meter above the sea level. Klyuchevskoi continues to extinct volcano Kamen at the SW side.

currences are rare. The former require energetic eruptions to feed both the summit craters and parasitic vents, and therefore are more likely to occur on relatively large and active volcanoes while the latter is a result of the balance between the mechanical strength of the sites and the magmatic forces at both the summit crater and the parasitic vent. All polygenetic volcanoes harbor the possibility of simultaneous main crater/parasite vent eruptions in the future. Frequencies of such simultaneous eruptions on a volcano are classified by qualitative measurement of volcanic activities and thus difficult to determine during prehistoric conditions. Therefore, here we will consider particular patterns of simultaneous eruptions of main craters and parasites on relatively large polygenetic volcanoes.

In the historical record of Etna [Imbò 1965], simultaneous eruptions have occurred about 10 times out of the 129 volcanic events during 693 B.C. to 1955. On Fuji, such occurrences have not been recorded since historical records began in 781 A.D. In Kamchatka instead we find another large volcano:

Klyuchevskoi ( $4850 \mathrm{~m}$ a.s.1.) is a stratovolcano of basaltic rocks measuring about $3000 \mathrm{~m}$ in relative height and connecting to an extinct volcano called Kamen at the SW flank. According to Vlodavetz and Piip [1969] and Fedotov et al. [1990], its age is about
$(7 \sim 8) \times 10^{3}$ yr. B.P. and as of 1990 there were 72 explosion cones and vents formed by parasitic eruptions mainly on the E flank. Distribution of the parasitic vents attributed to Fedotov et al. [1990, fig. 3] is reproduced in Figure 15 which includes prehistoric vents mentioned by Tokarev [1986, fig. 2].

If we assume distribution of the parasites as shown in Figure 15 to be circumferential, it is predicted that a prominent number will have a radius of about $10 \mathrm{~km}$. In the history of the volcano since 1697, 11 parasitic eruption events have been recorded, 5 of which were simultaneous with the summit eruptions.

Fedotov et al. [1990] discussed the activity of Klyuchevskoi during the period of 1932 1986 and the prospects for the future. According to their study, the summit crater of the volcano was filled with active lava at the time of the parasitic eruptions of 1938, 1945, 1966 and 1974. This may mean that the main conduit of the volcano also might be filled with magma. If this were the case, this would verify that parasitic eruptions of Klyuchevskoi would occasionally be related to the activity of the summit crater. On the SW flank of the volcano, there are scarcely any existing parasitic vents probably because structures related to Kamen volcano may be not be affected as much by the shear fracture model. The activities of the volcano suggest that its parasitic eruptions are not repeated at the same vents though the observation period is less than one century. This is a characteristic of parasitic vents and may be common to all volcanoes. Fedotov et al. [2010, fig. 19] imaged the plumbing system of the Klyuchevskaya group of volcanoes: formation of the parasites may be approximately agreeable to the shear fracture model due to the fact that the branches of the sub-conduits for parasites are located at the magma stop (shallow) or magma reservoir (deep) regions. Fedotov et al. [1990] found that the parasitic vents had migrated upwards from $450 \sim 500 \mathrm{~m}$ to $3000 \sim 3600 \mathrm{~m}$ in altitude during the period 1932 1986, linearly or exponentially with time. In fact, as they predicted, a large summit eruption occurred in 1994. We can interpret the upward migration of parasitic vents by the similar migration of branchpoint along the main conduit in the present model. The upward migration is reasonable because magma invades the main conduit from below before elevation. As for cyclic patterns of eruptions at parasitic vents and central vents, Takada [1997] proposed his time-series diagram of eruption sites on each parental volcano and intrusion distances of dikes to evaluate volcano growth, exemplifying Klyuchevskoi and many other volcanoes. He predicted that Klyuchevskoi should recur its pattern of upward parasitic vent migration in the near future. Recently, the volcano erupted from the summit in 2004. 
In the shear fracture model, the upward migration of parasitic vents can be mechanically interpreted as upward migration of pressure source or branch point along the main conduit. This is in agreement with the structural model of the volcano drawn by Fedotov et al. [2010, fig. 19].

Comparison of parasitic volcanism among Etna, Fuji and Klyuchevskoi: all of these volcanoes have large volumes, i.e. $3 \mathrm{~km}$ in relative heights and $35 \sim 50 \mathrm{~km}$ in basal diameters, and their rocks are all roughly andesite $\sim$ basalt; the corresponding ages of the volcanoes are diverse ranging from $10^{4}$ to $10^{6}$ years and they have manifested different activities during recorded history.

Etna: this is the oldest volcano of the group $\left(10^{6}\right.$ yr. B.P.) with 129 events since 693 B.C., 9 of which erupted simultaneously at summit and parasite vents.

Fuji: this is the second oldest volcano $\left(10^{4}\right.$ yr. B.P.) with 82 eruptions since 781 A.D. and no records of simultaneous eruptions.

Klyuchevskoi: this is the youngest volcano [(7 8) $\times 10^{3}$ yr. B.P. $]$ with 66 eruptions since 1697,9 of which were parasitic eruptions and 8 of which were simultaneous with summit eruptions.

On each particular volcano, the simultaneous eruptions of the main crater and parasitic vents are vigorously energetic actions in its plumbing system. Magma eruption rates of the three volcanoes are not comparable with each other because their active periods vary.

\section{Conclusions}

As a factor useful for characterization of parasitic vents, their spatial distributions around the central cones are classified into three categories: individually radial, directionally radial and annular. Classification depending on the radius type was justified after examining typical examples of each group, although the sample numbers may prove to be insufficient and ultimately may require amendment to this method. The idea of a "parasite gap" is tentatively proposed and interpreted by an empirical fact that parasitic vents are monogenetic.

Original formation of parasitic vents may be interpreted by some assumptions such as pre-existing volcano-tectonic crevices or magma-filled cracks: these conditions may be accidental in the specific volcanoes. In the present paper, the shear fracture analytical model is proposed from the standpoint of material mechanics as a method for providing a dilatational pressure origin beneath volcanoes. This model verifies the possibility of twin parasitic vents. Next, we can refer to several examples of observable twin parasitic vents. The last three eruptions of twin-type parasites on Sakurajima were reasonably well documented consid- ering the time period, and are discussed in detail in the present paper. Twin type parasites formed in prehistoric times are more difficult to confirm. Hence some of the present conclusions may have a possibility of modification in the future when new evidence is observed. In the shear fracture model, the branch depths are estimated by the relation $(D=1.2 r: r$ is radial distance). Branch points of sub-conduits of parasitic vents proved to be located at some depths of volcanic structures such as possible magma reservoirs and hypocenter regions of volcanic earthquakes, but their substance is unsettled. The shear fracture model may be not unique and may have some ambiguity when applied to interpretation of the formation of parasitic cones. The model should be reinforced as we obtain new knowledge on parasitic volcanisms.

Parasitic eruptions occurring simultaneously with activities of summit craters have been observed on some volcanoes. In the present paper, the discussion is first focused on the activities of Klyuchevskoi, and then the three volcanoes, Etna, Fuji and Klyuchevskoi, are comparatively discussed to find volcanological standards for such activities. However, the problem remains unsolved.

In a word, parasitic volcanisms are not auxiliary to main volcanoes but closely related to magma plumbing systems of the volcanoes.

Acknowledgements. This manuscript was significantly improved in both form and substance by critical reviews by Dr. M. Pistolesi and Dr. A. Fornaciai. I am greatly indebted to them. I owe my knowledge on Klyuchevskoi volcano to Prof. S. A. Fedotov. I am grateful to Ms. Sara Tanaka for editing the final version of this paper.

\section{References}

Anderson, E.M. (1936). The dynamics of the formation of cone-sheets, ring-dykes, and caldron-subsidences, Proc. Roy. Soc. Edin., 56, 128-157.

Azzaro, R. (2004). Seismicity and active tectonics in the Etna region: Constraints for a seismotectonic model, In: A. Bonaccorso, S. Calvari, M. Cotelli, C. Del Negro and S. Falsaperla (eds.), Mt. Etna: volcano laboratory, AGU Geophys. Monogr. Ser., 143, 205-220.

Behncke, B., and M. Neri (2003). The July-August 2001 eruption of Mt. Etna (Sicily), B. Volcanol., 65, 461-476.

Branca, S., and P. Del Carlo (2004). Eruption of Mt. Etna during the past 3200 years: A revised compilation integrating the historical and stratigragraphic records, In: A. Bonaccorso, S. Calvari, M. Cotelli, C. Del Negro and S. Falsaperla (eds.), Mt. Etna: volcano laboratory, AGU Geophys. Monogr. Ser., 143, 1-27. Calvari, S., and H. Pinkerton (2004). Birth, growth and morphologyic evolution of the 'Laghetto' cinder cone during the 2001 Etna eruption, J. Volcanol. 
Geoth. Res., 132, 225-239.

Chiarabba, C., P. De Gori and D. Patanè (2004). The Mt. Etna plumbing system: The contribution of seismic tomography, In: A. Bonaccorso, S. Calvari, M. Cotelli, C. Del Negro and S. Falsaperla (eds.), Mt. Etna: volcano laboratory, AGU Geophys. Monogr. Ser., 143, 191-204.

Corazzato, C., and A. Tibaldi (2006). Fracture control on type, morphology and distribution of parasitic volcanic cones: An example from Mt. Etna, Italy, J. Volcanol. Geoth. Res., 158, 177-194.

De la Cruz-Reyna, S., and I. Yokoyama (2011). A geophysical characterization of monogenetic volcanism, Geofis. Int., 50, 255-270.

Eichelberger, J.C., and P.E. Izbekov (2000). Eruption of andesite triggered by dyke injection: contrasting cases at Karymsky Volcano, Kamchatka and Mt. Katmai, Alaska. Phil. Trans. R. Soc. Lond. A 358, 1465-1485.

Fedotov, S.A., A.P. Khrenov and N.A. Zharinov (1990). The activity of Klyuhevskoi volcano in the years 1932-1986 and the prospects for the future, Volc. Seism., 9, 501-521.

Fedotov, S.A. (1998). Study and mechanism of the simultaneous 1996 karymsky Volcano and Akademii Nauk caldera eruptions in Kamchatka, Volc. Seism., 19, 525-566.

Fedotov, S.A., N.A. Zharinov and L.I. Gontovaya (2010). The magmatic system of the Klyuchevskaya group of volcanoes inferred from data on its eruptions, earthquakes, deformation, and deep structure, Volc. Seism., 4, 1-33.

Fornaciai, A., M. Favalli, D. Karátson, S. Tarquini and E. Boschi (2012). Morphometry of scoria cones, and their relation to geodynamic setting: A DEM-based analysis, J. Volcanol. Geoth. Res., 217-218, 56-72.

Furuya, M., S. Okubo, S. Wenke, Y. Tanaka, J. Oikawa, H. Watanabe and T. Maekawa (2003). Spatiotemporal gravity changes at Miyakejima Volcano, Japan: Caldera collapse, explosive eruptions and magma movement, J. Geophys. Res., 108 (B4), 2219; doi:10. 1029/2002JB001989.

Hildreth, W. (1983). The compositionally zoned eruption of 1912 in the Valley of Ten Thousand Smokes, Katmai National Park, Alaska, J. Volcanol. Geoth. Res., 18, 1-56.

Hildreth, W., and J. Fierstein (2000). Katmai volcanic cluster and the great eruption of 1912, Geol. Soc. Am. Bull., 112, 1594-1620.

Iguchi, M., T. Tameguri, Y. Ohta, S. Ueki and S. Nakano (2013). Characteristics of volcanic activity at Sakurajima volcano's Showa crater during the period 2006 to 2011, B. Volcanol. Soc. Jpn., 58, 115-135.

Imbò, G. (1928). Sistemi eruttivi Etnei, B. Volcanol., 15,
89-119 (in Italian).

Imbò, G. (1965). Catalogue of the Active Volcanoes of the World including solfatara fields, Part XVIII, Italy, Etna, 40-65.

Isshiki, N. (1960). The geological sheet map "Miyakejima”, scale 1:50,000, and its explanatory text, Geological Survey of Japan, 85 pp. (in Japanese with English abstract).

Isshiki, N. (1964). Mode of eruption of Miyakejima volcano in historical times, B. Volcanol., 27, 29-48.

Jaeger, J.C. (1964). Elasticity, fracture and flow, London, Methuen \& Co. LTD, 212 pp.

Kaneko, T., A. Yasuda, T. Shimano, S. Nakada, T. Fujii, T. Kanazawa, A. Nisizawa and Y. Matsumoto (2005). Submarine flank eruption preceding caldera subsidence during the 2000 eruption of Miyakejima volcano, Japan. B. Volcanol., 67, 243-253.

Kobayashi, T. (1988). Geological map of Sakurajima volcano, In: S. Aramaki, K. Kamo, M. Kamada and Kagoshima Prefectural Government (eds.), A guidebook for Sakurajima Volcano, Kagoshima Internat. Conf. on Volcanoes, 88 pp.

Kubota, S., and E. Berg (1967). Evidence for magma in the Katmai volcanic range, B. Volcanol., 31, 175-214.

Machado, F. (1962). Actividade do Vulcão do Fogo, Cabo Verde, Atlântida, 6, 3-191.

Machida, H., and F. Arai (1992). Atlas of volcanic ashes in Japan, Univ. Tokyo Press, 276 pp. (in Japanese).

Mikada, H. (1994). An elastic scattering theory and its application to the understanding of subsurface structure of Izu-Oshima volcano, Ph.D. Thesis, Univ. of Tokyo, 226 pp.

Nakamura, K. (1961). Stratigraphic studies of the pyroclastics of Ôshima volcano, Izu, deposited during the last fifteen centuries. II. Activity of parasitic volcanoes, Sci. Pap. Coll. Gen. Educ., Univ. Tokyo, 11, 281-319.

Nakamura, K. (1977). Volcanoes as possible indicators of tectonic stress orientation - principle and proposal, J. Volcanol. Geoth. Res., 2, 1-16.

Nakagawa, M., Y. Ishizuka, T. Kudo, M. Yoshimoto, W. Hirose, Y. Ishizaki, N. Gouchi, Y. Katsui, A.W. Solovyow, G.S.S. Alexander, G.S. Steinberg and A.I. Abdurakhmanov (2002). Tyatya Volcano, southwestern Kuril arc: Recent eruptive activity inferred from widespread tephra, The Island Arc, 11, 236-254.

Petrucci, G. (1935). L'Etna dal punto di vista magnetico, Atti della R. Accad. Sci., Lettere e Belle Arti di Palermo, 19, 3-5 (in Italian).

Poland, M.P., W.P. Moats and J.H. Fink (2008). A model for radial dike emplacement in composite cones based on observations from Summer Coon volcano, Colorado, USA. B. Volcanol., 70, 861-875. 
Takada, A. (1997). Cyclic flank-vent and central-vent eruption patterns, B. Volcanol., 58, 539-556.

Tanaka, H.K.M., and I. Yokoyama (2008). Muon radiography and deformation analysis of the lava dome formed by the 1944 eruption of Usu, Hokkaido Contact between high-energy physics and volcano physics, Proc. Jpn. Acad. Ser. B, 84, 107-116.

Tanaka, H.K.M., and I. Yokoyama (2013). Possible application of a compact electronics for multilayer muon high-speed radiography to volcanic cones, Geosci. Instrum. Method. Data Syst., 3, 1-30.

Thorarinsson, S. (1970). Hekla. A notorious volcano. Almenna Bókafélagid, Reykjavik, 61 pp.

Thorarinsson, S., and G.E. Sigvaldason (1972). The Hekla eruption of 1970, B. Volcanol., 36, 269-288.

Tokarev, P.I. (1986). Prediction of the Klyuhevskoi parasitic eruption in March 1983, Volc. Seism., 5, 491-496.

Tsuya, H. (1943). Geological and petrological studies of Volcano Fuji, V. 4. Structure and distribution of the parasitic volcanoes, B. Earthq. Res. I. Tokyo, 21, 376-393 (in Japanese with English abstract).

Tsuya, H. (1955). Geological and petrological studies of Volcano Fuji, V. 5. On the 1707 eruption of Volcano Fuji, B. Earthq. Res. I. Tokyo, 33, 341-383.

Ukawa, M. (2007). Low frequency earthquakes at Mount Fuji, In: S. Aramaki, T. Fujii, S. Nakada and N. Miyaji (eds.), Fuji volcano, Yamanashi Inst. of Environ. Sci., 161-172 (in Japanese with English abstract).

Vlodavetz, V.I., and B.I. Piip (1969). Catalogue of the active volcanoes of the world including solfatara fields. Part VIII, Kamchatka, kliuchevskoi, 76-86.

Yamaguchi, K. (1975). Research on Sakurajima Volcano - Geologocal and petrological researches of the surrounding area of Kagoshima Bay and Sakurajima volcano, Educ. Soc. Earth Sci. Jpn., 128 pp. (in Japanese).

Yokoyama, I. (1962). Geomagnetic anomalies on three Italian volcanoes, Annali dell'Osservatorio Vesuviano, Sesta Serie, 4, 173-188.

Yokoyama, I., and M. Seino (2000). Geophysical comparison of the three eruptions in the 20th century of Usu volcano, Japan. Earth Planets Space, 52, 73-89.

Yokoyama, I. (2013). Parasitic eruptions on Sakurajima volcano, B. Volcanol. Soc. Jpn., 58, 91-102.

Yokoyama, I. (2014). Krakatau caldera deposits: revisited and verification by geophysical means, Annals of Geophysics, 57 (5), S0541.

Corresponding author: Izumi Yokoyama,

The Japan Academy, Ueno Park, Tokyo, Japan;

email: iyokoyama@joy.ocn.ne.jp.

(C) 2015 by the Istituto Nazionale di Geofisica e Vulcanologia. All rights reserved. 